\title{
COMPOSTOS NOMINAIS DO HITOPADEXA (1)
}

\section{Maria Luísa F Miazzi}

A composição é dos mais interessantes processos do sânscrito (2), evoluindo mormente no período clássico; no védico aparecem alguns compostos curtos ( 3 ), mas, com o tempo, sua extensão e freqüência aumentam, comprometendo o uso da flexão (4) De início, representa a junção de dois termos, cujo sentido não indica necessariamente a soma de ambos: a esse primeiro composto agregam-se outros, sendo extraordinário o comprimento que alguns atingem.

O primeiro elemento (assim chamado, ainda que represente o conjunto de diversos) apresenta-se como forma invariável - que não se declina ou é mero tema de palavra sujeita a declinação (5) - e aparece em geral no grau fraco; no tocante ao segundo, jamais será um pronome, pelo que só terá valor nominal, recebendo a flexão competente (6) Também no caso de figurar uma raiz no segundo termo,

(1) - Em edição escolar desse fabulário célebre, adotamos a grafia aportuguesada com $\times$ no título, para evitar a pronúncia com a sibilante; aliás, essa forma já fora vernaculizada por Mons. Dalgado.

(2) - Procede, aliás, do indo-europeu, como se pode depreender da semelhança entre os compostos védicos e os de Homero (Macdonell, A Vedic Grammar, p. 267).

(3) - Geralmente são constituídos por dois membros, surgindo três no máximo: purva-kama-krtvan, "que satisfaz desejos anteriores"

(4) - Courbin (Gramm. élém. du Sanskrit Classique, p. 16) demonstra-o através do composto anekavidha-prasada-harmya-valabhi-niryuha-çata-samkula - $h$, "ornado de uma centena (ou centenas) de torrinhas e de balcões e de palácios e de terraços multiformes", que, a rigor, se decomporia em: samkula-h çatena (ou çatair) niryuhanam valabhinam ( $c a$ ) harmyanam (ca) prasadanam (ca) anekavidhanam.

(5) - No pronome, contudo, vigora a forma do nominativo singular neutro, para qualquer gênero ou caso.

(6) - Algumas particularidades observam-se no final do primeiro membro, como alterações vocálicas, abreviações, passagem de temas em $-a$ e -i-aos de -a- (mahant- a maha- é normal), adjunção do sufixo -ka adjetival, etc. 
sua função continuará a de adjetivo ou substantivo, sempre no grau fraco (7)

O sentido é, em verdade, a parte mais atraente, porquanto o mesmo composto pode apresentar às vezes duas acepções diferentes, dependendo do contexto. Assim, maha-ratha- tanto pode significar "carro grande" como "aquele que possui um carro grande", isto é, indicará uma qualidade ou a posse. Também a composição apresenta-se coordenativamente, indicando pares (dual) ou a pluralidade, surgindo às vezes da união de masculinos e femininos um neutro coletivo; e, ainda, pode ser expressa a distribuição, mediante formas repetidas ou justapostas.

Os gramáticos indianos costumam dividir os compostos, semanticamente, em quatro grupos, designados pelos nomes que lhes atribuiu Pânini (e até se usam para outras línguas): dvandva (copulativos), karmadharaya e tatpurusa (determinativos cujos membros estão em relação direta ou subordinada) e bahuvrihi (possessivos)

Whitney (8) agrupa-os em três classes, com subdivisões: copulativos, determinativos (dependentes e descritivos) e secundários (possessivos e compostos cujo membro final é regido) Para Macdonell (9), a tríplice divisão é a mais conveniente, da mesma forma; apenas, para os primeiros de Whitney, dá o nome de coordenativos e engloba os últimos sob a designação genérica de possessivos Servem-se, entretanto, os autores ocidentais da nomeclatura dos indianos, que usam a par da gramatical, embora com certas deslocações (10) E verdade que alguns retornam a quatro classes, como Varenne (11), que usa a classificação de Pânini, Renou (12), que desdobra muito as divisões tríplices mencionadas, acrescentando a dos "anormais", e Mayrhofer

(7) - Se a raiz terminar em - $a$, abreviar-se-á (de STHA, p. ex., rathastha- "que se mantém sobre o carro, i. é, guerrei-o") e, se a vogal for breve, receberá um -t- (de ÇRU, p. ex., dirgha-çru-t, "que tem o ouvido longo ou fino").

(8) - Sanskrit Grammar, § 1247, pp. 480-482.

(9) - A Sanskrit Grammar, § 185, p. 169.

(10) - Bergaigne não usa os termos sânscritos consagrados, atendo-se à nossa nomenclatura, ao classificar os compostos em primitivos, derivados, copulativo e compostos de compostos. Os "primitivos", cujo primeiro membro não altera a forma nem a função do segundo, correspondem aos tatpurusa e karmadharaya, e os "derivados",que chegam a adjetivar-se, aos bahuvrihi (Manuel pour étudier la langue sanscrite, p. 279-282). E verdade que Whitney adotou semlhante critério com os "secundários", por oposição aos demais ("primários"), que não tiveram uma unificação.

(11) - Grammaire du Sanskrit, p. 50-52.

(12) - Grammaire Sanscrite, p. 86-96. 
(13), cujo esquema, separando os indeclináveis, parece-nos mais prático e, por esse motivo, endossamos.

Distribuímos, pois, os compostos nominais do Hitopadexa, do seguinte modo:

1) Coordenativos (dvandva), que pressupõem a união de substantivos ou adjetivos pela cópula $e$ (raramente $o u$ );

2) Determinativos, os quais se subdividem basicamente em dependentes (tatpurusa), cujo primeiro membro depende sintaticamente do segundo, e descritivos (karmadharaya), em que a relação entre este e aquele se manifesta predicativamente. Em ambos os casos, podem os compostos ser constituídos por substantivos e adjetivos ou equivalentes. Quanto aos karmadharaya, de caráter essencialmente adjetival, encerram também, segundo alguns autores, os numerais (dvigu), mas preferimos, dada a sua natureza, constituir com eles o terceiro grupo de determinativos: tatpurusa, karmadharaya e dvigu (14)

3) Possessivos (bahuvrihi), que indicam certa qualidade possuída pelo ser ou uma determinada situação em que se encontra;

4) Adverbiais (avyayibhava), cujo primeiro elemento é uma palavra indeclinável e a segunda, um acusativo neutro.

No HITOPADEXA indubitavelmente os mais numerosos são os tatpurusa (571); seguem-se os bahuvrihi (282) e, em ordem bem decrescente, os dvigu (8) Johnson, cujo léxico nos forneceu todo esse elenco (15), separa ainda os compostos cujo segundo termo é a raiz verbal - que figuram alhures entre os tatpurusa - denominandoos kwip, e cita apenas 9, na maioria formados com VID (16).

Exemplificá-los-emos apenas, dando ênfase aos mais raros, a fim de não ultrapassar os limites estabelecidos para este artigo.

COORDENATIVOS - dvandva "par"

(13) - Sanskrit-Grammatik, p. 101-103.

(14) - Entre os determinativos incluem ainda alguns (cf. Macdonell, $A$ Sanskrit Grammar, p. 175) os compostos adverbiais (avyayibhava), mas seguimos aqui os gramáticos indianos.

(15) - Hitopadesa: the Sanskrit Text, pp. 113-278.

(16) - Ainda faz referência a um tipo que designa por chwi, enumerando 15; porém, embora entrem formas participiais, são do domínio da composição verbal. 
São constituídos geralmente por substantivos e, em menor escala, por adjetivos. Embora específicos do sânscrito, ocorrem também

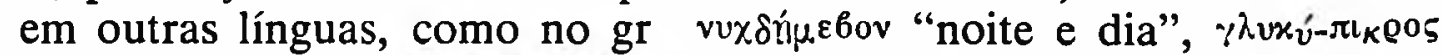
"doce e amargo", $\lambda \varepsilon v_{\kappa} 0-\mu \dot{t}^{\prime} \alpha_{5}$ "branco e preto", no lat. su-ove-taurilia "sacrifícios de porco, ovelha e touro", reci-procus "que vai para trás e para a frente" (17), etc. Comparem-se, também, caturdaça e quattuordecim (18) com os modernos vierzehn, fourteen, etc.

No védico, surgem particularmente aplicados a divindades mitraváruna, dyáva-prthiví - com forma dual e o acento distinto em cada elemento (19), mas também no plural - aho-ratrani "dias e noites", ajaváyas "cabras e ovelhas (mesmo alguns numerais restaram dessa época: dva-daça).

Na língua clássica, apresentam-se com flexão dual ou plural do segundo membro e, ainda, sob a forma de um coletivo. Exs.: hastyaçvau "um elefante e um cavalo" e hasty-açvah "elefantes e cavalos"; dual jaya-parajayau "vitória ou derrota", suta-bharye "o filho e a esposa", bija-yoni "o germe e a matriz"; pl. putra-pautrah "filhos e netos", sarameya-marjarah "cães e gatos", ou, no loc. pranapanodanesu "durante a respiração e a expiração", etc.; col. aharniçam "dia e noite", dasyustrajavikam (dasy-ustra-aja-avika-m) "a serva, a camela, a cabra e a ovelha' etc. Adjs.: vrtta-pina "redondo e gordo", çukla-krsna "claro e escuro" etc.

No HITOPADEXA, como vimos, os dvandva são muito escassos, mormente em relação aos tatpurusa e bahuvrihi, mal chegando à casa dos sessenta. Indicamos alguns, inicialmente no nominativo dual (m. e n.) e plural; a seguir, veremos outros casos e adjetivos.

a) Dual - Masc.: aditya-candrau "sol e lua, uc-cayapacayau (apacaya) "prosperidade e declínio", dampati "casal, marido e mulher" (20), mrga-jambukau "o veado e o chacal", sundopasundau "Sunda e Upasunda" (nome de dois irmãos), harsa-krodhau "alegria e raiva"; n. : ratry-ahani "noite e dia")

b) Plural - Masc .: kaka-kurma-mrgakhavas (mrga-akhavas de $a k h u$ ) "o corvo, a tartaruga, o veado e o rato", patotpatas (pata $e$ upata) "quedas e reerguimentos"

(17) - Aplica-se tal sentido especialmente ao mar; depois, o de "recíproco, altamente". Compöe-se de reco-s e *proco-s, derivados das partículas re e pro (Ernout-Meillet, Dict. Etym. Langue Latine; s. v.).

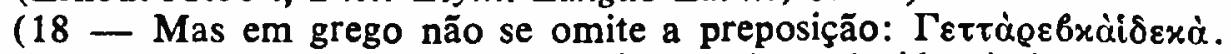

(19) - Desses compostos, na o-igem talvez devidos à justaposição, ficaram vestígios no sânscrito: mitra-varunau, dyava-prthivyau.

(20) - Propriamente dam-pati "senhor da casa" 
c) Outros casos:

Sing.: acus. n. balabalam "força e fraqueza"; loc. n. tirthaçrama-sura-sthane "num lugar de peregrinação: eremitério e templo;

Dual: acus. m. guna-dosau "inocência e culpa"; instr. n. danamanabhyam "por um presente e honra"; gen. m. sevya-sevakayos "de servido e servidor, i. é, de patrão e criado"; gen. n. tejas-timirayos "de luz e escuridão";

Plural: acus. m. stri-bhrtyan "mulheres e servos"; instr. n. vigyana-vikrama-yaçobhis "por conhecimento, valor e renome"; gen . m. marana-vyadhi-çokanam "de morte, doença ou tristeza"; gen. n . kastha-pasana-vasasam "de madeira, pedra e roupas"; loc. n. nadyadri-vana-durgesu "em rios, montanhas, bosques e passagens difíceis"

d) Adjetivos: nom. pl. m. uttamadhama-madhyamas "bom, mau e indiferente" ou "alto, baixo e médio", papa-punya- "corrompido ou virtuoso" (21), priyapriye "no agradável e desagradável" (22), sarasara- bom e mau", nimnonnata- "deprimido e levado, alto e baixo"

\section{DETERMINATIVOS}

Às duas grandes classes que abrangem - dependentes (tatpurusa) e descritivos (karmadharaya) -, acrescentamos os numerais (dvigu), muitas vezes incluídos entre os últimos, como dissemos anteriormente.

1 - Dependentes - tatpurusa "seu homem, seu criado"

O próprio nome revela que existe um dependência entre os menbros do composto, ou seja, o primeiro determina o segundo, substituindo qualquer um dos casos oblíquos. Essa relação casual pode verificar- se entre um substantivo e um adjetivo, determinando o último elemento a natureza do compostos. Geralmente quando pede - quanto ao sentido - acusativo, instrumental, ablativo ou locativo, o segundo termo é um nome verbal; mas é um nome comum, se dativo ou genitivo, sendo este o mais corrente dos casos.

(21) - Aparecem os adjetivos em vários casos e gêneros, razão por que somente damos o tema.

(22) - Citamos um loc. sing., porém há outros casos; por isso, doravante só indicaremos o tema, como fazemos nos outros tipos de compostos. Nos dvandva tornava-se necessário esclarecer gênero e número, tanto que assim os classificamos. 
Em outros idiomas também os encontramos, como no gr. irno- $\mu a ̉ x o s$

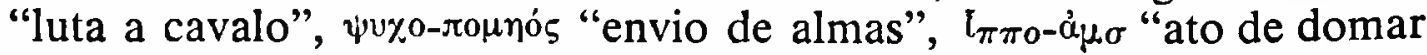

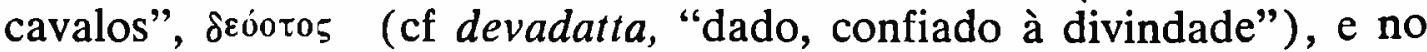
lat . montivagus (22), juris-consultus, iudex (24), credo (25), animadverto (26), etc. Em línguas modernas temo-los no al. königs-haus por "des königs Haus" ingl. man-hater, man-hated, etc. (27)

$\mathrm{Na}$ época védica temos vários exemplos, dos quais reproduzimos alguns, distribuidos segundo a relação casual:

a) Acusativo - Sempre encontramos, neste caso, um nome verbal no segundo termo, podendo indicar o agente (havir-ád "que come a oblação", bhuri-dávan "que dá muito") como a ação (vrtra-hátva "o fato de matar Vrtra");

b) Instrumental - agni-dagdhá "queimado pelo fogo", devá-tta (28), "dado pelos deuses", bala-vijñayá "para ser reconhecido por sua força";

c) Dativo - vakmaraja-satya "fiel aos ordenadores de hinos", viçvá-çambhu "salutar para todos";

d) Ablativo - go-ja "produzido por vacas", tivra-sú-t "comprimido a partir da massa de levedura (azeda);

e) Genitivo - raja-putrá "filho do rei" (29), deva-kilbisá "ofensa contra os deuses" (30);

f) Locativo - uda-plutá "nadando na água", bandhu-kšit "que mora entre parentes"

Obs.: Às vezes pode ocorrer flexão no primeiro termo, especialmente no acusativo, com freqüência no locativo, mas escassamen-

(23) - Esse tema em monti- (vagus, -fer, -cola, -gena, etc) deve-se ao fato de ser um composto poético formado sobre os modelos gregos em segundo Ernout-Meillet, o. c., p. 733.

(24) - Está por *ious-dex, "o que indica a lei, juiz".

(25) - A forma original seria cred-dho, ou seja, "eu ponho fé, creio"

(26) - De adverto "voltar o espírito em direção a, observar".

(27) - Gray,Foundations of Language, p. 163.

(28) - Aqui -tta está por datta.

(29) - Confira-se rajá-putra, com diferente acentuação; é um bahuvrihi, pois significa "o que tem por filho(s) um (ou mais) reis(s)".

(30) - Estranharíamos a tradução, mas se trata de genitivo objetivo. 
te nos demais casos. Exs.: acus. abhayam-jará "que granjeia segurança", dhanam-jayá "que vence a presa"; instr.: vaca-stena "ladrão pelo discurso, i, é. que prejudica secretamente com as palavras"; dat: Jivo-já "produzido pelo céu"; abl.: divo-rúc "brilhando do céu"; genit.: gnas-páti "marido de uma mulher divina"; loc.: divi-ksayá "que habita no céu";rathe-stha "que permanece no carro, i. é., guerreiro"

$\mathrm{Na}$ língua clássica, proliferam os compostos (e mais extensos):

Acusativo - jaya-prepsu "desejando vitória", jivita-ksaya "diminuição de vida", nagara-gamana "que vai à cidade", madhuçcut "que destila o mel", muhurta-sukha "prazer por um instante", svargagati "subida ao céu", varsa-bhogya "para ser usufruído por um ano";

Instrumental - ahi-hata "morto por uma cobra",indra-gupta "protegido por Indra", dharma-patni "esposa pela lei", bhanyartha "riqueza adquirida pelo grão", mat-tapo-virya-sambhrta- "cheio da força resultante do meu ascetismo" (31), matr-sadrça "semelhante à sua mãe";

Dativo - go-hita "bom para o gado", padopaka (pada-upaka "água para os pés", paropakara "serviço prestado aos outros", masanicaya "acumulação por um mês", visnu-balin "que se oferece a Vichnu";

Ablativo - anna-ja "oriundo de comida", garbhastama "o oitavo do nascimento", caura-bhaya "medo de ladrões", bhavad-anya "diferente de V. Excia.", rajya-bhrasta "caído (expulso) do reino", candraçucitara "mais brilhante que a lua";

Genitivo - asmat-putra "nosso filho", bharataçrestha "melhor dos Bharatas", murkha-çatani "centenas de loucos", viç-pati "senhor do clā";

Locativo - açva-kovida (32) "experimentado em cavalos", rtvij "que sacrifica em boa estação", grama-vasa "casa na aldeia", purusanrta "não verdadeiro sobre os homens", hrdayavidh "trespassado no coração"

Obs.: a) Mesmo no sânscrito clássico, perduram ocasionalmente formas flexionadas no primeiro membro do composto: parasmaipada "palavra por outro", yudhi-sthira "firme no combate" (nome próprio).

b) Convém ainda lembrar que, no fim de um tatpurusa, alguns termos adquirem sentido especial, como sucede com viçesa ("tipo especial de" subentendendo "escolha", que passa ao adj. "preemi-

(31) - Desdobrando, teríamos: "sambhrta-s viryena tapasas mama".

(32) - Também o primeiro elemento é considerado um genitivo plural. 
nente"), antara (lit. "diferença", mas que se torna "outro", "especial") e artha ("finalidade", significando, no acusativo: "no interesse de", "em favor de", "por causa de").

No HITOPADEXA, o número de compostos deste tipo é o maior de todos, alcançando quase seis centenas; a grande maioria é constituída pela união de dois substantivos - pressupondo o genitivo e, a seguir, substantivo e particípio passado - relação geralmente de intrumental e, enfim, de substantivo e adjetivo. Outros casos são de presunção mais rara. Ainda nos tatpurusa incluímos os denominados "nomes-raízes"

Indicamos, a seguir, o quadro básico:

1) Substantivo + substantivo

a) Aqueles cujo sentido indica uma relação de genitivo, do primeiro para o segundo membro, são em número elevadíssimo e só vamos citar uma lista diminuta:

Genitivo - angangi-bhava "relação recíproca do corpo e seus membros", añjali-karman "ato de submissão", anna-dana "doação de alimento", a-bhaya-vac "certeza de encorajamento", arthosman (artha-usman) "chama ou condição de riqueza", asmat-putra "meu (nosso) filho", asmad-dhrdaya "meu (nosso) coração", atithya-satkara "os bons ofícios da hopitalidade", atma-vrttanta "autobiografia", arta-rava "grito de dor de alguém", iccha-sampad "aquisição ou obtenção de desejos", istaka-grha "casa de tijolos", katha-samgraha "uma coleção de estórias", kapota-rajan (33) "o rei dos pombos", kanda-pata "queda ou vôo de uma flecha", kusuma-stavaka "coleção ou conjunto de flores, uma grinalda", keli-kanana "jardim de prazer, de luxo", ksurabhanda "caixa de navalha", gaja-pungava (34) "grande ou nobre elefante", gandharva-vivaha "casamento por consentimento mútuo sem qualquer cerimônia", guna-stuti "panegírico, louvor da virtude", grhacchidra "problema familiar" go-pradana "doação de gado", ghanagarjita "o rugido do trovão", caksur-visaya "esfera do olho, alcance da vista", janma-bhumi "solo nativo, terra do berço", jivita-vyaya "sacrifício de vida", gyana-niçcaya "retidão de conhecimento, certeza", tac-chakti "sua força (dele)", taj-jñana "conhecimento daquilo", tad-

(33) - Sempre lembramos que está sendo indicado o tema da palavra (o nominativo aqui não seria raja, porém -rajas, devido à composição).

(34) - De pun-gava "touro", geralmente usado no fim de um composto, denotando preeminência. 
ança "uma porção disso", tan-naça "sua destruição", tapo-vana "floresta de penitência", trnolka "tocha de feno ou palha", danda-naryaka "chefe policial (dono do bastão)", dosa-bhiti "medo da ofensa", naradhipa "senhor dos homens, rei", nrpa-vallabha "favorito real", paksirajya "a soberania das tribos aladas", pandita-sabha 'assembléia de pândites ou letrados", para-paksa "o lado do inimigo", pura-vrttakatha "estória do tempo antigo", banik-putra "filho de mercador", bhavad-vacana "vosso (de V Revcia.) discurso", bhumy-eka-deça "uma porção de território", mad-deha "meu corpo", mano-ratha "um desejo (carro do espírito)", mantra-phala "fruto do conselho", masatraya (m) "um trio de meses, i. é, três meses", muktavali "colar de pérolas", yan-murdhan "cuja cabeça", yauvana-darpa "orgulho da juventude", raja-karya "assunto do rei", loka-pravada "dito popular", varsambu "água da chuva", vitteha (vitta-iha) "desejo de riqueza", vipad-daça "um estado de desgraça", vivaha-catustaya (m) "um casamento de quatro esposas", viçvasa-patra "vaso para beber, i. é, digno de confiança", vihara-grha "casa de brinquedo teatro", çaran-megha "nuvem de outono", çista-sabha "concelho de estado", sva-puccha "cauda de um cão sem prestimos", san-masabhyantara "espaço incluído em seis meses", sankhya-matra "quantidade de números, mera numeração", samrdddhi-samaya estação de prosperidade", sadhya-sadhana "a realização do que pode ser feito", suvarna-dana "dádiva de ouro", sneha-ccheda "interrupção da amizade", sva-bhu-tyaga "abandono do próprio país", hasti-badha "morticínio de elefante", himagama "a estação fria, inverno"

Obs.:

a) Um caso de flexão dentro de um composto encontramos em gavam-pati "dono dos bois";

b) Quantos aos compostos formados por dois substantivos que implicam em outras regências (35), são poucos e ocorrem mais no dativo e locativo:

Dativo - karya-sandeha "dificuldade para a ação", caranabharana "ornamento para o pé", pati-vrata "fidelidade ao marido", (36), pari-dhana-valkala "tecido para vestimenta", bhuta-daya "compaixão

(35) - Baseamo-nos nas fundamentais e não em casos esporádicos, pois é frequiente o uso de um caso por outro.

(36) - Com prefixo, poderia ocasionalmente haver um acusativo em exemplos como este, mas aqui temos um genuíno dativo (Varenne, $\$ 168, \mathrm{p}$. 110). 
para com todas as criaturas" (37), yajña-chaga "um bode para sacrifício", yuddho-dyoga "preparação vigorosa e ativa para a guerra", yusmad-artham "para vós" (38);

Locativo - durga-vyasana "defeito ou franqueza numa cidadela", drumalaya "morada em árvores", satyotkarsa "excelência na verdade";

$\mathbf{N}$ : Ainda podemos assinalar algum raro caso de instrumental (atmau-pamya "semelhança a si próprio"(39), cañcu-prahara "picada com o bico", etc.

\section{2) Substantivo + participio passado}

Também muito numerosos, pressupõem para o tema do substantivo uma relação de instrumental, caso do agente, porém outras várias regências se observam:

a) Acusativo - aça-vibh nna (vi + BHID) "desapontado quanto à esperança", kroça-matra-sthita "que permanece à distancia de um 'cos' ou 'kroxa', diva-supta "adormecido de dia";

b) Instrumental - anek-opavasa-klista "desgastado por muito jejum", atmadista "aconselhado por si próprio, auto-admoestado", upanad-gudha (GUH) "coberto com um sapato" (40), kirti-yuta (YU) "associado a renome, célebre", jara-parinata (pari + NAM) "curvado pela idade", daya-yukta "munido de piedade", dhana-hina (HA) "abandonado pelo dinheiro, pobre (41), payasa-dagdha "queimado com mingau de aveia", prabhu-krta "feito por um senhor", lobhamohita (MUH "entontecido pela cobiça", visa-digdha (DIH) "envenenado", v:ra-samanvita "atendido por guerreiros", vyadhi-durbhiksa-pidita "gasto devido a doença e fome", harsa-yukta "cheio de alegria""

Obs.: São freqüentes os compostos com arta $(\mathrm{a}+\mathrm{R})$ "afligido": ksudharta "faminto", gharmarta "oprimido pelo calor", trsarta "an-

(37) - Poderíamos incluir o presente entre os casos de locativo (até de genitivo), a que estão conexos vocábulos designativos de "compaixão, confiança, negligência" etc. (Macdonell, § 204, p. 198).

(38) - Eis um dos casos atrás mencionados (p. 188) da diferenciação de sentido de artha no acus., num final de composto.

(39) - Além de suas funções próprias de acompanhamento, associação (com) e, daí, meio, instrumento (por), estão entre os usos do instrumental alguns especiais como o de "igualdade", "semelhança" (Whitney, § 281, p. 94)

(40) - O instrumental é o caso aplicável para designar algo com que se cobre algo (Gonda, $\$ 114$, III, p. 91). ablativo.

(41) - O adj. verbal designativo de "abandono" usa-se também com o 
gustiado pela sede", duhkharta "aflito de dor", çitarta "atormentado pelo frio", çokarta "com muita dor", himarta "sofrendo de frio", etc;

c) Dativo - kamaçakta "aplicado à luxúria" (42), bhartr-bhakta devotado a um senhor", çaranagata "que veio para proteção, refúgio";

d) Ablativo - upa-cara-pari-bhrasta "destituído de bondade", dhana-hina "abandonado pela riqueza, i . é, pobre", papa-rahita (RAH) "livre do pecado", bandhu-hina "sem parentes", mati-hina "destituído de espírito, ignorante", ripu-varjita "livre de um inimigo", sthanabhrasta "caído ou removido da situação natural";

e) Locativo - kara-prapta "obtido, seguro na mão", guna-lubdha (43) "ávido de qualidades", jala-badha (BANDH) confinado numa rede", panka-magna (MAGG) "afundado na lama", mano-gata "o que vai na mente, i. é, o pensamento", sva-hasta-gata "caído na minha própria mão", haryarudha "montado em cavalo"

OBS .: Ainda ocasionalmente são encontrados alguns particípios futuros (os gerundivos no fim dos compostos, como duhkha-cchedya "para ser conquistado com dificuldades", suci-bhedya "o que pode ser atravessado com uma agulha", skandhopaneya "para ser carregado nos ombros", etc.

\section{3) Substantivo + adjet:vo}

Embora de menor ocorrência, também aparecem no texto, expressando as relações de:

Acusativo (44) - an-eka-sançayo-cchedin (ucchedin: "destruidor") "aquele que resolve muitas dúvidas", artha-kari "a que produz vantagem, vantajosa, alpecchu (alpa e icchu)" que procura pouco, moderado", krta-naçaka "que destrói, que determina perda de ação";

Instrumental - kopakula "movido pelo ódio", gunanvita "dotado de virtudes", papa-timira "cego por pecado", dur-bhiksa-vyasanin "angustiado pela fome", madandha "cego por orgulho ou paixão", vasavaçesa-malina "sujo de restos de gordura"

(42) - Com ÇAK "poder, ser capaz de" "tanto o dativo como outros casos (instr., gen., loc., acus.) são usados. locativo.

(43) - $O$ adjetivo veibal de $L U B H$ no fim do composto requer sentido regesse.

(44) - Traduziríamos pelo genitivo com um agente ou adjetivo que o 
Genitivo - ud-yoga-samartha "capaz de esforço", udara-bharanamatra-kevalecchu "desejo só do mero enchimento da barriga";

Ablativo - cudavalambin (cuda "crista" e ava lambin, adj.) "que pende do alto, que se reclina";

Locativo - açvadhika "eminente, superior quanto a cavalos", kala-yodhin "que luta na estação ou tempo adequado", gyana-crestha "preeminente em sabedoria", vidya-vrddha "velho em conhecimento", sandhi-kuçala "esperto na arte de formar aliança"

OBS.:

1) Em viçvasa-ghataka "traidor de confiança", ou "o que mata a confiança" temos a presença do sufixo de adjetivo -KA- já citado.

2) Algum raro caso de aposto, como vindhya-cala "a montanha Vindhya", inclui-se no nominativo e não genitivo (45).

3) Com a flexão expressa, temos um acusativo: vasum-dhara "que carrega tesouros, i. é, a terra"

Nomes raízes $(K W I P)$ - Entre os tatpurusa são incluídos ainda (46) compostos que têm uma raiz como segundo membro, denominados nomes-raízes por Varenne, kwip por Johnson (47) Exs.: grama-ja (JAN) "nascido na aldeia", brahma-vid "que conhece o brahma", madhu-çcut "que destila o mel", veda-jña (JÑ) "que sabe o veda", sarva-jit (JI) "que vence o mundo", svayam-bhu "que existe por si, independente"

No HITOPADEXA encontramos apenas nove exemplos que apresentam relação de acusativo entre os dois membros (embora posamos traduzi-los por adjetivos, com o complemento mais apropriado):

a) 4 casos com a raiz VID: dharma-v d "que conhece o dever" ou "dotado do sentido de justiça", niti-vid "versado em política", sandhi-vid "relacionado com alianças" e citra-karma-vid "experimentado na arte de pintar";

45) - Cf. Whitney, § 267, p. 89 e $\S 295$, p. 99.

(46) - Ver Macdonell, $\S 187$, p. 172; Gonda, § 110, p. 88; Varenne, $\S 72, \mathrm{p} .51$.

(47) - O termo é estranho e não se encontra alhures, como é o caso de chwi, que emprega para os compostos verbais formados com os auxiliares KR, BHU, AS (exs. do HITOPADEXA: krodi-karoti "abraça", dhvaji-krtya "tendo feito um estandarte", hariti-krtas "tornado verde", bahuli-bhavanti "tornam-se abundantes", etc. 
b) 2 casos com a raiz BHR: bhu-bhrt "o que sustenta a terra", i. é, "um rei" e a-patra-bhr-t "um apreciador de pessoas indignas";

c) 2 casos com a raiz BHUJ: kantaka-bhuj "o que come espinhos" e a-pathya-bhuj "que come cousas não toleradas pelo estômago;

b) 2 casos com a raiz BHR: bhu-bhrt "o que sustenta a terra", $\mathrm{i}$. velmente"

\section{2 - Descritivos - karmadharaya (48)}

Conforme indica o nome desta classe, trata-se de compostos em que há descrição do segundo membro pelo primeiro, que tem geralmente caráter atributivo, mas pode ter o de aposição.

Embora o valor adjetival do primeiro termo seja mais frequiente, mesmo em outras línguas (cf. gr. axoó-лo lat. angiportus "rua estreita", al.Jungfrau, etc), também ocorre o de substantivo - vale por uma sentença nominal - em que é comum en-

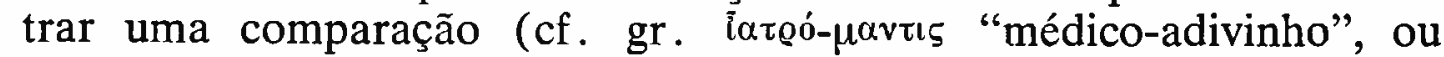
seja, "um médico o qual é também um mago", ingl. man-mountain "homem-montanha", i. é, "um homem que é como uma montanha")

Consequientemente, distribuímos os compostos karmadharaya segundo a natureza gramatical do primeiro elemento: substantivo, adjetivo ou invariavel (advérbio, preposição, partícula). Mais comum é a de adjetivo (antara-purusa "alma interior", ardha-marga "meio caminho", nilotpala "lótus azul", priya-sakhi "querida amiga", maharaja "grande rei"), incluído o particípio passado, mas o substantivo também ocorre na função aposicional (jaya-çabda "a palavra conquista" amatya-raksasa "o ministro Rakchasa", expressando às vezes a comparação (rajarsi "rei-sábio", i. é, "rei que é como sábio", narasimha "homem-leão" i. é, "homem que tem as qualidades de um leão", kanya-ratna "jóia de menina", i. é, menina bela como uma jóia") (49), como ainda a de um invariável (a-mitra "sem amigo", adhi-loka "o mundo mais alto", su-jana "homem virtuoso", su krta "bem feito", $d v i$-ja "nascido duas vezes", etc. )

Essa é a divisão em que se enquadram também exemplos védicos:

(48) - O vocábulo karmadharaya é de incerta origem. Entretanto, temse-lhe atribuído o significado de "o que estabelece a ação": ou "o que se lembra dos atos", mas com dúvidas (cf. Varenne, p. 50-51)

(49) - No caso de comparação, pode o composto apresentar um substantivo e adjetivo: megha-çyama 'escuro como a nuvem", hima-çiçira "frio como o gelo" 
Substantivo - purusa-mrgá "antílope macho", vrsá-kapi "homem macaco";

Adjetivo - krsna-çakuni "corvo" (propriamente "pássaro preto"), purvahná "de manhã";

Invariável - aksnaya-drúh "que prejudica erradamente", puróhita "colocado à frente, ou seja, padre ligado a um príncipe", adhirajá "supremo-rei", sam-vatsará "o ano todo"

No HITOPADEXA, os karmadharaya com adjetivo no primeiro membro ultrapassam a casa dos sessenta (acrescida de uma dezena de particípios), enquanto aparece uma meia dúzia com substantivo; indicamos alguns dos últimos e limitamo-nos a exemplificar apenas os outros, devido a seu grande número.

1 - Substantivo - a-kala-kusuma "flor que brota fora do tempo", a-vivekadhipa-pure (adhi-pa) "uma cidade de senhor injusto", açraya-bhuta (50) "que protege, que se tornou o ponto de apoio, o refúgio", panya-stri "mulher que é mercadoria, prostituta"

Obs.: Teríamos caso de invariável na maioria dos que entram nos compostos mencionados (a-kala "má época", a-viveka "injusto" e adhi-pa "soberano, senhor"), porém aqui fazem parte do primeiro membro.

2 - Adjetivo - (51) a-ksaya-loka "mundo imperecível (céu)", ardha-koti "metade de um crore (52), ardha-ratra "meia-noite", alpabala "pequena força", alpopaya "poucos meios", usna-kala "tempo quente, verão", kalyana-vacana "belas palavras, discurso amigo", krsna-sarpa "serpente negra" kiyad-dura "uma pequena distância" (53), cira-mitra "um velho amigo", tivrapaurusa "intenso heroísmo", nitya-pariksana "constante investigação", nirjana-vana "uma floresta solitária", parameçvara "poderoso senhor", parasparokara "mútuo benefício", priya-vastu "um objeto favorito", bhuri-vrsti "excessiva chuva", mahakula "uma grande família", maha-panka "um grande pân-

(50) - No segundo membro aparece às vezes o particípio bhuta "tornado", com o sentido de "sendo", quando se une a um substantivo aposicional (que se adjetiva); é o que sucede com ratna-blhuta "sendo uma jóia" (já ratni-bhuta "tornada uma jóia' se enquadra entre os compostos ve:bais).

(51) - Incluem-se adjetivos pronominais. sistema)

(52) - Equivalente a cinco milhões, ou dez (o maior número do antigo

(53) - $\mathrm{O}$ interrogativo aqui funciona como atributo. 
tano", maha-pandita "grande filósofo", maha-siddhi "grande resultado ou sucesso", mahahi "uma grande serpente", mahodadhi "o receptáculo das águas, i. é, o oceano", çita-kala "tempo frio", çubhalagna "um momento feliz", sat-patra "pessoa digna ou virtuosa" (54), san-mitra "amigo verdadeiro", sama-kala "mesmo tempo", sarva-bhuta "toda criatura", sadhukta (sadhu-ukta) "um dito acertado", sitotpala "lótus branco", sukhi-sva-bhava "diposição feliz ou contente"

Obs.: Podem aqui incluir-se os compostos cujo primeiro termo é um particípio passado (os autores geralmente não diferenciam):

chinna-druma "árvore cortada", jirnodyana (jirna de JR e udyana) "um jardim velho, negligenciado", dattasana "um assento presenteado", praptavasara "tempo adequado, ocasião própria" (prapta de AP), samskrtokti (sam $+s+k r t a+u k t i)$ "expressão polida", su-guptalekha "carta muito íntima", hata-jyotir-niçitha "noite escura (de claridade morta)"

\section{3 - Numerais - dvigu "duas vacas" (56)}

São aqueles cujo primeiro termo é um numeral cardinal e designam um conjunto. Aparecem geralmente como um coletivo, na forma do neutro singular ou, mais raro, como um feminino em -i. Exs.: triloka "três mundos, o conjunto de três mundos", catur-yuga "as quatro idades", tri-ratra "espaço de três noites", sad-gunya "as seis qualidades (de um príncipe)"

No védico são indicados alguns neutros: tri-yugá "período de três vidas", dvi-rajá "batalha de dois reis", daçangulá "comprimento de dez dedos" (57).

E óbvio que pode um composto destes assumir o caráter de um possessivo (bahuvrihi) : assim, tri-guna-m significa "as três qualidades" mas tri-guna-s será "o possuidor de três qualidades"

(54) - O particípio sant- de $A S$, além do sentido próprio (existente"), significa também "bom, justo, virtuoso"

(55) - É normal a disposição de purva no final da palavra (drsta-purva "visto antes", etc.) .

(56) - São incluídos geralmente, como dissemos, entre os karmadharaya, mas preferimos, com Mayrhofer (p. 102), separá-los dos adjetivos (e mesmo dos pronomes, considerada a moderna classificação de classes de palavras) .

(57) - Note-se que Macdonell (A Vedic Grammar, § 189, p. 278) os inclui entre os possessivos substantivados (po-ém mesmo estes são subdivididos por ele em possessivo karmadharaya e tatpurusa. 
No HITOPADEXA encontramos alguns dvigu, formados com os cardinais $5,6,8$ e 100, na maioria tornados possessivos: pañcaçata-m cinco centos", "quinhentos", sat-karna-s "com seis orelhas", sad-guna-s "que tem seis qualidades", sad-vargas-s "dominado pelos cinco sentidos e o Manas, os seis inimigos interiores do homem", astaguna-s "dotado de oito qualidades" asta-yudha-s "guarnecido com oito armas", çata-dvara-m "uma saída que apresenta cem portões"

\section{POSSESSIVOS - bahuvrihi “(que tem) muito arroz" (58)}

São compostos adjetivos (embora o segundo termo possa constar de um substantivo), que indicam ser o sujeito possuidor de alguma coisa.

Um determinativo passa facilmente a possessivo, razão por que só o contexto nos poderá esclarecer quando o composto é tatpurusa ou bahuvrihi. Na verdade, bahuvrihi significa "muito arroz", mas assume valor adjetival para indicar "o possuidor de muito arroz", tripad é o tema de "três pés", mas adjetiva-se em "aquele que possui três pés" (cf. gr. ז@--ro $\delta$, lat. tri-ped-) ou, ainda indra-çatru tanto será o substantivo "inimigo de Indra" como a expressão adjetiva "tendo Indra como inimigo"

E comum esse tipo de composição em várias línguas: cf. gr.

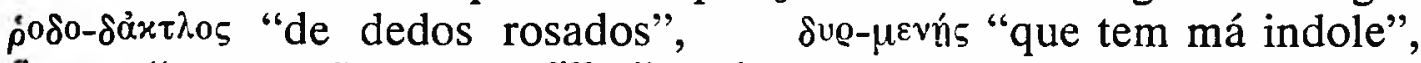
$\tilde{\alpha}-\alpha \iota_{\text {s }}$ "que não tem filho"; lat. magn-animus "que possui grande ama"; al. Dick-kopf "tendo cabeça dura"; ingl . great-minded "dotado de grande espírito"

Para o védico, cita Macdonell vários exemplos, porém distribuídos em bahuvrihi do tipo karmadharaya, tatpurusa e substantivados:

a) possessivos karmadharaya: áçva-parna "que tem cavalos por asas, i. é, cujas asas são cavalos", ugrá-bahu "de braço poderoso", rajá-putra "tendo reis como filhos", hatá-matr "cuja mãe foi morta";

b) possessivos tatpurusa: diví-yoni "tendo origem no céu", rayáskama "tendo um desejo como riqueza";

c) possessivos substantivados (subentende-se o nome): an-apatyá "que não tem filhos", brhád-diva "que habita no alto do céu", i. é, um mago (mas, cf. acento, brhad-divá "deusa"), su-parná "de belas asas" i. é, "pássaro"

(58) - Gonda explicita o nome pela frase: "vrihir bahur yasya, sah" (Gonda, p. 89) 
$\mathrm{Na}$ língua clássica, os bahuvrihi são muito comuns. O segundo termo é sempre um substantivo, de sorte que apenas diferem estes compostos pela natureza do primeiro; pode ele ser um substantivo (tapodhana "aquele cuja riqueza é a ascese", praja-kama "cujo desejo é a rescendência", yajña-kama "que tem o desejo do sacrifício" (59), mas também pode ocorrer um adjetivo (divya-rupa "que possui forma divina", bhima-parakrama "que tem tremenda bravura", mahatman "magnânimo, que tem grande alma") ou participio passado (hataputra "que tem um filho morto", cujo filho foi morto", jitendriya cujos sentidos foram vencidos" (60), gatayus "aquele cuja vida se foi", i. é, "morto"; e ainda indeclinável (abala "sem força", adho-mukha "com o rosto para baixo, i. é, deprimido"), an-udra "que não tem água", dvi-pad "bípede", dur-mukha "que tem um rosto feio", durmanas "cuja mente é maldosa", sa-bharya (61) "acompanhado de sua esposa", tatha-vidha "de uma tal espécie" (vidhi).

\section{OBS.:}

1) Dá-se também, entre os possessivos, a transferência para a classe dos substantivos: su-hrd "o que tem bom coração" passa a "amigo", etc.

2) Também se notam compostos em que entram associados tipos diversos, como çitosna-kiranau (çita-usna-kiranau) "que tem o raio de luz do frio e do quente", i. é, "lua" e "sol", onde o bahuvrihi contém um dvandva.

3) Alguns vocábulos encontram-se no final do composto com sentido alterado:

a) kalpa "modo" e praya "parte principal" aparecem significando "como" e "quase";

b) para, parama, que significam "alto", principalmente quando usados como masculinos, têm o sentido de "absorto em", "concentrado em" (lit. "tendo como a cousa principal. "), como em cintapara "imerso no pensamento";

c) matra "medida" com o sentido de "somente" no ex.: rat:matra "o prazer e nada mais";

(59) - Poder-se-ia traduzir como tatpurusa: "que deseja realizar um sacrifício".

(60) - Na verdade o sentido é ativo: "que dominou os próprios sentidos"

(61) - Lembre-se que damos o tema sempre e aqui se trata de composto masculino (o segundo membro é bharya, feminino). 
d) adi (m) "começo", adika "que principia por", adya "primeiro (substantivado), e, às vezes, prabhrti "começo" passam a indicar: "e o resto", "e mais os outros", "etcetera" (ex.: s.mhadayah "o leão e os outros animais").

4) Os nomes que designam a "mão" (e também outras partes do corpo) usam-se no fim do composto: dandapani "tendo um pau na mão", çastra-hasta "tendo uma espada na mão"

5) E comum o emprego de sufixos - $k a$ - (adjetival), como sapatni-ka "acompanhado pela esposa" e de -in unido a palavras como dharma, çila, çobha, varna (ex.: vara-varn-in "de excelente cor").

6) No início do bahuvrihi, um particípio passado equivale a gerúndio ou locativo absoluto (tyakta-nagara "tendo deixado a cidade").

7) Alguns bahuvrihi apresentam no primeiro membro um tema de infinito e, no segundo, manas ou kama Ex.: vaktumanas "eu reflito para dizer", tyaktukama "que deseja abandonar"

No HITOPADEXA, que é rico em compostos deste tipo, observamos tais peculiaridades, razão por que as mencionamos em conjunto. Em geral, os bahuvrihi, aqui, têm como primeiro elemento um substantivo ou particípio passado, mas também invariáveis, alguns adjetivos e temas de pronomes, numerais, etc. Muitas vezes um adjetivo é, na verdade, um particípio (çuddha "puro" de ÇUDH, a-rakta "róseo" de RAÑJ").

Seu número, como vimos, atinge quase os 300 , mas, tendo muitos deles o mesmo primeiro termo, exemplificá-los-emos reduzidamente. Ainda citamos "compostos de compostos", que, embora se analisem no esquema adequado, sempre se constituem de dois membros.

Dividimo-los a seguir, corforme a natureza do primeiro membro:

1) Substantivo - alasaya-nibandhana "que se origina na indolência", kuça-hasta "que tem erva 'kuxa' na mão (pata)", ksatriyadharma "tendo a profissão militar", kharga-pani "com a espada na na mão", danstra-nakha-langula-praharana "armado com dentes, garras e rabo", duta-mukha "falando por um embaixador (com a boca de um mensageiro)", droha-buddhi "de mente maliciosa (que tem pensamento de hostilidade)", pati-prana "esposa dedicada (aquela cujo marido é a sua vida)", pati-vrata "a que tem devoção pelo marido, 
virtuosa", payo-mukha "tendo leite na face", raja-sançraya "tendo reis para seu refúgio (dependente de reis)", visa-hrdaya "tendo veneno no coração", visnu-çarma-naman "que tem por nome Vichnuxarman", çastra-pani "com arma na mão", sagaranta (62) "rodeado pelo oceano".

\section{2) Formas nominais}

a) Particípio presente médio: dolayamana-mati "com o espírito vacilante";

b) Absolutivo (ou gerúndio): krta-krtya "tendo feito o seu dever";

c) Particípio passado; krta-dhi "de compreensão cultivada, i. é, inteligente", ksina-papa "tendo sofrido as consequiências do pecado, i. é, "purificado", gata-vibhava "cuja riqueza se foi i. é, pobre" galita-nakha-danta "tendo os dentes e garras caídos (sem dentes e garras)", jata-pratyaya "tendo a confiança levantada", jata-viçvasa "tendo a confiança excitada", drsta-dosa "cujo erro foi encontrado, i) é, descoberto, nastendriya "pessoa cujos orgãos dos sentidos são destruídos", prasanna-mukha "de rosto alegre (disposto)", pra-hrsta-manas "satisfeito no espírito, muito alegre", prapta-kala "alguém cujo tempo de destino (hora) chegou (63), baddhañjali "com as palmas juntas, bhagna-janu "de joelho quebrado", mukta-hasta "de mão aberta", viraktiprakrti "cujos chefes ou principais comandantes são desleais", sañjatersya (sañjata de sam + jata + irsya) "tornado invejoso (que tem a inveja desenvolvida)", stabdha-krna "tendo as orelhas erectas", hatajyoti "sem estrelas, escuro (cujas estrelas estão extintas)", h:na-varna "de uma casta vil (abandonada)", hrsta-pustanga "que tem o corpo alegre e nutrido"

3) Adjetivo - alpa-prabhava "de pequeno poder, insignificante", alpa-çakti "que tem pouca força", ghorakrti (akrti) "de horrível aspecto", tulya-vança "de raça igual", dirgha-maya "doente por longo tempo", nila-varna "de cor azul", papa-mati "de espírito mau", papaçaya (açaya "mal intencionado (que tem a mente pecaminosa)", punyaika-karman "aqueles cujos atos são apenas bons", bahu-ripu "que tem muitos inimigos", manda-gati "de ida vagarosa", maha-khata

(62) - No texto aparece a forma do acus. f. sing. sagarantam. E um tipo interessante de composto, terminado em anta "limite, fim". Literalmente teríamos: "que tem o mar como fim"

(63) - Também poderia ser um karmadharaya com sentido de "estação adequada' 
"que tem um grande fosso", mahodaya "dotado de grande esplendor", laghu-cetas "de espírito baixo", sama-virya "de igual força"

(4) Pronomes e adjetivos pronominais: anya-manas "de espírito volúvel (que tem pensamento diverso)" anyonya-kalaha "brigando (que tem disputas) com um e outro", ubhaya-guna possuidor de ambas as qualidades", kim-varataka "alguém para o qual não interessa o dinheiro" (64), kidrg-vyaparavan (vyapara + -vant) "de que profissão ou vocação?", tad-anta "terminando nisto, cujo fim é este"

5) Numerais - eka-citta "cujo pensamento gira sobre uma só cousa", ekartha "que tem um só objeto", pañcanga "que tem cinco membros" (65).

6) Invariáveis: a-durga "sem fortaleza", an-açraya "destruído de asilo ou lugar de refúgio", yavad-ayuh-pramana "medido pela duração da vida", sa-karuna "piedoso, que tem compaixão", sa-dhana "rico", sa-natha "que tem patrão", sa-phala "frutífero", sa-yatna "ocupado, ativo", sa-viçesa "excelente, especial (que tem particularidade)", sa-sainya-bala-vahana "com guardas, armas e veículos", su-jala "que possui água clara ou doce", sotsaha (sa-utsaha) "estrênuo (com vigor)"

7) Compostos de compostos: a-guna-çila "que tem maus hábitos, i. é-, indigno", an-anya-pratikriya "incapaz de fazer ulterior resistência", ava-nata-kaya "abaixado (que tem o corpo inclinado para baixо)", a-skhalita-prayana "não tropeçando na marcha (que tem passo não vacilante)", ahita-hita-vicara-çunya-buddhi "aquele cujo intelecto é vazio de discriminação entre o bem e o mal", a-marananta "durando pela vida, cujo término é a morte", uc-chrita-pani "com a mão estendida", un-nata-çiras "levantando a cabeça (tendo a cabeça não abaixada").

OBS.: Entre os bahuvrihi inclui Johnson citram-citram "estranho, muito estranho", que é preferível classificar como iterativo (66).

(64) - Ao pé da letra é "oque diz: o que é um varataka? (espécie de moeda)", "um gastador"

(65) - Pañcangas no nom sing.: não se confunda com o dvigu, pois, neste caso estaria no neutro, designado um conjunto.

(66) - São classificados à parte, em alguns autores, ou grupados com os distributivos.

Do tipo gr.

"para a frente, para a frente" ou seja, sempre à frente", lat. quisquis "quem quer que", já temos no védico exemplo tais que pañca-pañca "cinco de cada" ou dáme-dame "em todas as casas", no sâncrito clássico uttarottara "cada vez mais alto", paras-param "reciprocamente", anyo" nyah "um e outro" 


\section{ADVERBIAIS - avyay.bhava "estado indeclinável (67).}

São os que apresentam como primeiro termo um indeclinável (advérbio, preposição, etc.) e, como segundo, um substantivo no acusativo neutro singular.

São comuns os exemplos, como anu-rupam "de acordo, conformemente", praty-aksam "à frente dos olhos, visivelmente", sa-vinayam "polidamente", sa-kopam "com raiva", yatha-kamam "conforme o prezer", yatha-çakti "segundo a habilidade", yavaj-jivam "por toda a vida"

No HITOPADEXA, assinalamos 43 compostos desta espécie, na maioria formados com yatha (16) e sa (19); e ainda 4 casos de prati, 2 de nir e 2 de yavat:

a) nir-dayam "sem piedade", nir-bhayam "sem medo";

b) prati-vatam "contra o vento", praty-aham "diariamente";

c)yatha-kartavyam "como deve ser feito", yatha-karyam "como é correto (ser feito) fazer", yatha-bhimatam "conforme o pensamento de alguém", yatha-vakaçam "de acordo com a oportunidade", yatha-vyavaharam "conforme o uso", yatha-çrutam "como se tem ouvido", yathestam "segundo o desejo", yathocitam "adequadamente";

d) yavacchakyam "ao máximo de meu poder", yavaj-jivam "para o resto da vida";

e) sa-cakitam "timidamente", sa-tvaram "com pressa", sa-darpam "orgulhosamente", sa-rosam "indignamente", sa-vismayam "com surpresa", sakanksam "com desejo", saçcaryam "com espanto", sastangam "com os oito membros (mãos, pés, calcanhares, testa e peito).

\section{CONCLUSÃO}

De exposto, verifica-se que o emprego da composição nominal tão característica do sânscrito - na obra que nos serviu de base, o HITOPADEXA, é marcante não só pela frequiência, como também pesa riqueza de nuances que permite à expressão. Era nosso intento

(67) - Propriamente avyaya significa 'imperecível", "constante", "inalterável". Na composição verbal é comum aparecer a expressão ayayibhavati "torna-se indeclinável" 
classificar todos os exemplos coletados, mas a tarefa excederia em muito a disponibilidade de espaço oferecido ao artigo, pelo que procuramos os mais sugestivos, que revelassem aspectos semânticos interessantes.

De um milhar de compostos examinados, seis centenas são constituídas pelos que determinam o nome, estabelecendo uma dependência sintática entre os membros (tatpurusa), e pouco menos de um terço, pelos ditos bahuvrihi, cujos elementos perdem a individualidade a fim de exprimir posse de uma qualidade ou condição; não chegam a uma centena os descritivos (karmadharaya), de caráter atributivo ou aposicional, e superam um pouco a metade dela os coordenativos (dvan$d v a)$ Abaixo dos cincoenta figuram compostos que têm por primeiro termo um invariável (avyayibhava) e uma dezena de numerais representando um conjunto (dvigu).

Esse traço - da grande maioria dos dependentes - é normal; e cumpre lembrar que muitas vezes se dá a passagem de um tatpurusa, ou mesmo karmadharaya, a um bahuvr hi, segundo o contexto, o que pode engrossar o número destes. Ex.: prapta-kala pode designar "o tempo adequado" (karmadharaya ou "aquele que chegou" bahuvrihi); tadanta não significa apenas "o fim disto" como ainda "aquele cujo fim é este"

Os compostos são constituídos não só pela união de dois ou mais substantivos, como também pela de adjetivos, pronomes, formas nominais (é comuníssimo o particípio passado) e até de invariáveis com o substantivo.

Formações como essas há em otras línguas, embora ocasionais. Assim, podemos comparar o tema scr. tri-pad-com o lat. tri-ped-,

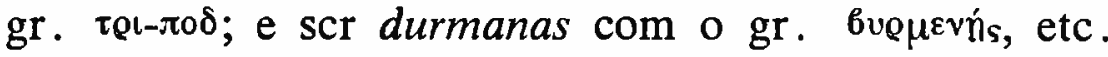

Quanto ao sentido, além do próprio, costuma haver um figurado, ou, também, dois termos se unem para designar por suas características outro em concreto. O primeiro caso é o do tipo de mano-ratha "carro do espírito", donde "desejo", pati-prana "a que tem por alento o marido", isto é, "esposa dedicada"; gata-vibhava "aquele cuja riqueza se foi", ou seja, "pobre"; çitosna-kiranau "o duo que tem um raio de luz do frio e do quente", portanto, "a lua e o sol"; mati-hina "o abandonado pela mente", isto é, "o ignorante", etc. No tocante ao segundo, basta citar krsna-çakuni "pássaro preto" equivalendo a "corvo", bhu-bhrt "aquele que sustenta a terra", ou seja, "o rei"; $v a$ - 
sum-dhara (68) "a que carrega tesouros", donde "a terra", etc; mas em gaja-pungava, lit. "elefante-touro", o segundo elemento adquire natureza adjetival para designar "um grande elefante"

Dessa maneira, a versatilidade obtida pela linguagem alcança inusitados e infindáveis matizes, que assinalam o sânscrito como língua de composição peculiar.

\section{BIBLIOGRAFIA}

Bergaigne, A. - Manuel pour étudier la langue sanscrite, H. Champion, Paris, 1966.

Courbin, H. - Grammaire élémentaire du Sanskrit Classique. A. Maisonneuve, Paris, 1931.

Gray, L. - Foundations of Language, The Macmillan Co., New York, 1939.

Gonda, J. - Manuel de grammaire élémentaire de la langue sanskrite (trad. da ed. alemã do orig. hol.), A. Maisonneuve, Paris, 1966.

Johnson, F. - Hitopadesa: the Sanskrit Text, 2.a ed., St. Austin, London, 1864.

Macdonell, A. - A Sanskrit Grammar for Students, 3a ed. (1927), Oxford Univ. Press, reimpr. de 1968.

Macdonell, A. - A Vedic Grammar for Students, Oxford Univ. Press (1).

Mayrhofer, M. - Sanskrit-Grammatik, Sammlung Göschen 1158-1158 a, Walter de Gruyter \& Co., Berlin, 1965.

Renou, L. - Grammaire Sanscrite (vol. I e II reunidos), A. Maisonneuve, Paris, 1961.

Stchoupak, N, Nitti L. e Renou, L. - Dictionnaire Sanskrit-Français, A. Maisonneuve, Paris 1959.

Varenne J. Grammaire du Sanskrit, "Que sais-je ?"n.o 1416, Paris, 1971.

Whitney, W. D. - Sanskrit Grammar, Cambridge, Mass Harvard Univ. Press e Oxford Univ. Press, London, 1950.

(68) - $\mathrm{O}$ índice flexional de acusativo aqui se manteve, excepcionalmente, conforme explicado atrás, à página 187 . 